\title{
Diversidade florística e índices arbóreos de escolas no município de Formoso do Araguaia, Tocantins
}

\section{Floristic diversity and arboreal indices of schools in Formoso do Araguaia municipality, Tocantins}

\author{
André Ferreira dos Santos ${ }^{1 *}$, Gildeani Costa ${ }^{2}$, Lucicléia Mendes Oliveira ${ }^{3}$, Patrícia Aparecida de Souza ${ }^{4}$, Kaio Cesar Cardoso \\ de Lima Fonseca Alves
}

\begin{abstract}
Resumo: A arborização nas escolas exerce papel importante na melhoria desses ambientes, tornando-os mais atrativos e agradáveis para a comunidade educacional e serve como exemplo e fonte de aprendizagem contínua. Assim, objetivou-se fazer o levantamento das espécies e índices arbóreos em nove escolas no município de Formoso do Araguaia, Tocantins. O referido estudo foi realizado em nove escolas públicas do município, desconsiderando-se as escolas particulares. Para saber o número de alunos existentes, cada escola forneceu a relação dos matriculados no período. Fez-se o senso e a identificação da vegetação arbórea presente nos pátios das nove unidades. Os dados de altura foram levantados com auxílio de um clinômetro, com uma trena coletou-se o diâmetro de copa e o tamanho da área de cada pátio escolar e através do Microsoft Excel fez-se os cálculos dos índices de Densidade Arbórea (IDA), Sombreamento Arbóreo (ISA) e de Área Verde (IAVE). Nas escolas foram encontrados 158 indivíduos pertencentes a 14 famílias botânicas representadas por 27 espécies, distribuídas em 15 nativas e 12 exóticas. A escola João Queiroz destacou-se com o melhor ISA $(28,19 \%)$ e a Hermínio Azevedo Soares pode ser considerada como referência pelos índices encontrados (ISA $=19,037 \%$ e IDA=0,97\%). As espécies nativas mais frequentes foram Licania tomentosa (Benth.) Fritsch, Mangifera indica L. e Cassia fistula L. Os maiores índices arbóreos (IDA e ISA) foram verificados nas escolas João Queiroz e Hermínio Azevedo Soares e o menor na Silas Raimundo Milhomem dos Santos.
\end{abstract}

Palavras-chave: Arborização urbana. Índice de sombreamento arbóreo. Pátio escolar

\begin{abstract}
The afforestation in schools plays an important role in improving these environments, making them more attractive and enjoyable for the educational community and serves as an example and source of continuous learning. Thus, the objective was to make a survey of arboreal species and indices found in nine schools in Formoso do Araguaia, Tocantins. This study was carried out in nine public schools in the city, disregarding private schools. To know the number of existing students, each school provided the list of those enrolled in the period. The sense and the identification of the arboreal vegetation present in the schoolyards of the nine units were made. The height data were collected with the aid of a clinometer, with a measuring tape was collected the tree crown diameter and the area of each schoolyard and through Microsoft Excel the calculations of the Arboreal Density Index (ADI), Shading Arboreal Index (SAI) and Green Area Index (GAI). In schools were found 158 individuals belonging to 14 botanical families represented by 27 species, distributed in 15 native and 12 exotic. The João Queiroz school excelled with the best SAI (28.19\%) and the Herminio Azevedo Soares school can be considered as reference by the indices found $(\mathrm{SAI}=19.037 \%$ and $\mathrm{ADI}=0.97 \%)$. The most frequent native species were Licania tomentosa $($ Benth.) Fritsch, Mangifera indica L. and Cassia fistula L. The largest arboreal indices (ADI and SAI) were observed at schools João Queiroz and Herminio Azevedo Soares and the lowest indices at Silas Milhomem Raimundo dos Santos school.
\end{abstract}

Key words: Urban arborization. Shading arboreal index. Schoolyard

\footnotetext{
*Autor para correspondência

Recebido para publicação em 24/07/2016; aprovado em 10/06/2017

${ }^{* 1}$ Professor, Doutor, Curso Engenharia Florestal - Universidade Federal do Tocantins, Gurupi-TO; 33113564, andrefs@uft.edu.br

${ }^{2}$ Engenheira Florestal, Universidade Federal do Tocantins, gil.costa18@hotmail.com

${ }^{3}$ Bióloga, Doutora, Universidade Federal do Tocantins, lucicleiabiologa@ gmail.com

${ }^{4}$ Professora, Doutora, Departamento de Ciências Agrarias, Universidade Federal de São João Del Rei -Sete Lagoas-MG, patriciaapsouza@ufsj.edu.br

${ }^{5}$ Engenheiro Florestal, Mestre, Universidade Federal do Tocantins, kcclfa@ hotmail.com
} 


\section{INTRODUÇÃO}

A arborização urbana se refere ao conjunto de áreas com vegetação especialmente arbórea, encontrada em diversos espaços dentro da cidade, como ruas, avenidas ou parques (SILVA et al., 2007), as quais podem viabilizar a preservação e a conservação das plantas e ainda a interação do homem com a natureza.

Esta proporciona benefícios para o ambiente urbano frente às alterações das condições naturais que foram necessárias para realização de construções. Nesse sentido, a vegetação remanescente e aquela introduzida na área urbana promovem a retenção de poluentes pela fotossíntese executada principalmente pelas folhas, minimiza a temperatura do meio, a copa das árvores fornece sombra e proteção térmica, exercendo um papel antipoluidor capaz de reduzir cerca de $10 \%$ o teor de poeira, e promove conservação genética da flora (TOLEDO; SANTOS, 2008; ALVES et al., 2011).

O uso de espécies da flora nativa, especialmente aquelas da região geográfica na qual a cidade está inserida é essencial do ponto de vista ecológico, adaptativo e funcional, principalmente por garantir as relações ecológicas coevolutivas e genéticas, de dispersão de propágulos (pólen e sementes), envolvendo fauna e flora dentro do ambiente urbano e por conservar o material genético autóctone (PAIVA et al., 2010).

No entanto, o que se observa nas vias públicas de muitas cidades brasileiras e em pátios escolares é a utilização de espécies exóticas. Por exemplo, nas vias públicas de Rio Branco no Acre, $78 \%$ das espécies eram exóticas (PAIVA et al., 2010), em Lages-SC foram 54,54\%, onde predominava Ligustrum lucidum W.T. Aiton. (KÜSTER et al., 2012). Nos pátios escolares de Curitiba-PR, por exemplo, das 170 espécies encontradas em 30 escolas, 60,59\% dessas eram exóticas (BIONDI et al., 2008); em Monte Carmelo-MG foram $71,79 \%$ das espécies encontradas em apenas uma escola (SANTOS; LOPES, 2010), enquanto em Cuiabá-MT verificando-se um equilíbrio entre as espécies nativas e exóticas (CALLEJAS et al., 2014).

Considerando-se todos os benefícios da arborização, torna-se evidente que a mesma não pode está restrita apenas as ruas, praças e parques, devendo ser valorizada também nos ambientes escolares, uma vez que pode servir como um instrumento de educação ambiental, local de interação sociocultural, de realização de atividades recreativas e funcionais, inclusive como ambiente para a promoção de aulas práticas das disciplinas de ciências naturais, entre outras (KÜSTER et al., 2012). Além disso, pode viabilizar a exploração da educação ambiental como estratégia para mostrar aos alunos a importância da implantação e preservação da arborização do ambiente escolar (BOLZAN; GRACIOLI, 2012)

Um exemplo fácil e prático de se aplicar temas relacionados a arborização nas escolas é por meio do plantio de espécies da flora local. Cuja atividade pode ser realizada logo após serem tratados assuntos sobre o meio ambiente e a importância da relação entre o homem e a natureza, contribuindo desta forma para a formação da conscientização ambiental e possibilitando a exploração de outras disciplinas, como biologia, ecologia (ANDRADE; SILVA, 2008) e também a ornamentação.
O estudo da arborização nas instituições de ensino se faz necessário por viabilizar a interação entre os alunos e a natureza, além de possibilitar o conhecimento de espécies nativas da flora brasileira, aproveitar o espaço físico desses ambientes para introduzir assuntos relacionados à educação ambiental e fortalecer o conteúdo ministrado pelos professores. Segundo Fagundes et al. (2015), para atingir essa finalidade é importante envolver os alunos em projetos interdisciplinares para então, construir o conhecimento e a aprendizagem, bem como despertar a criatividade e desenvolver a cultura ambiental.

O conhecimento das espécies que compõe a arborização das escolas, e a quantidade de árvores necessárias para proporcionar um conforto térmico é essencial para esses espaços físicos.

Diante do exposto, objetivou-se realizar o levantamento das espécies arbóreas encontradas no pátio de nove escolas no município de Formoso do Araguaia, Tocantins.

\section{MATERIAL E MÉTODOS}

\section{Localização da área de estudo}

O município de Formoso do Araguaia, Tocantins (Figura 1), está localizado na região sudoeste do estado, tendo como coordenadas geográficas $11^{\circ} 47^{\prime} 48^{\prime \prime}$ de latitude sul e $49^{\circ} 31^{\prime} 44^{\prime \prime}$ de longitude oeste com altitude de $240 \mathrm{~m}$ sobre o nível do mar. Possui uma área territorial de 13.423,26 km² e possui uma população estimada de 18.733 habitantes de acordo com os dados do Instituto Brasileiro de Geografia e Estatística (IBGE, 2014).

Figura 1. Localização do município de Formoso do Araguaia, Tocantins.

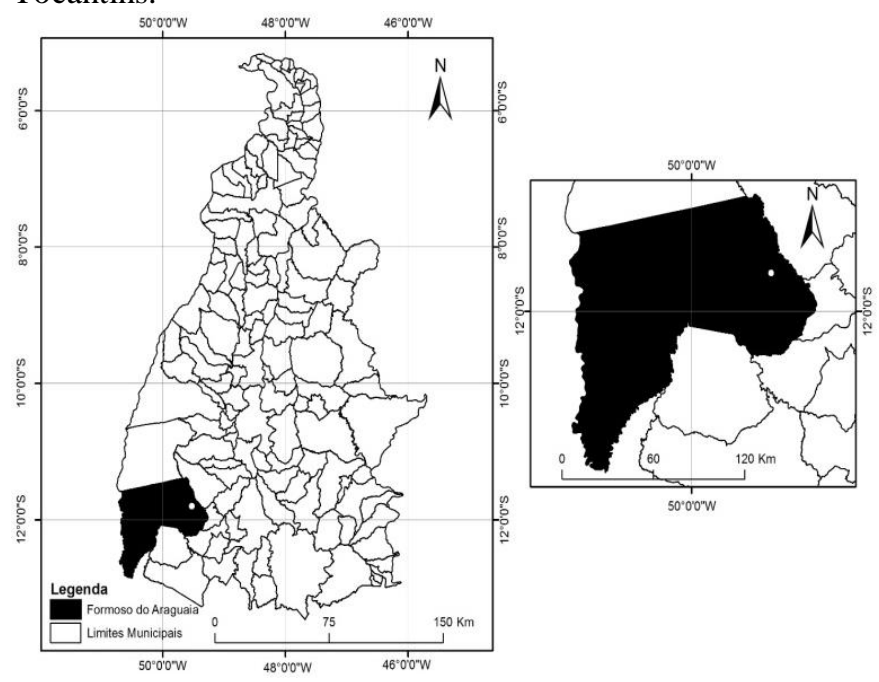

O clima da região é úmido com moderada deficiência hídrica no inverno, apresentando variação pluviométrica média anual entre 1.400 e $1.700 \mathrm{~mm}$, distribuindo-se no verão em torno de 390 e $480 \mathrm{~mm}$ ao longo dos três meses consecutivos, cujas temperaturas são mais elevadas (TOCANTINS, 2012).

Para a realização deste estudo, as escolas particulares foram desconsideradas. Assim, a pesquisa foi desenvolvida em nove instituições (Tabela 1) de ensino público da área urbana de Formoso do Araguaia, dentre estas, seis são municipais e três estaduais nas quais havia alunos de ensino fundamental e médio. Para saber o número de alunos, foi solicitada para cada unidade escolar a relação de estudantes matriculados no referido ano letivo. 
Tabela 1. Identificação das escolas estudadas de Formoso do Araguaia, Tocantins.

\begin{tabular}{|c|c|c|c|c|c|}
\hline $\mathrm{N}^{\mathrm{o}}$ & Nome das Escolas & Tipo & Grau & $\mathrm{N}^{\mathrm{o}}$ de alunos & Área $\left(\mathrm{m}^{2}\right)$ \\
\hline 1 & Silas Raimundo M. dos Santos & M & $1^{\circ}$ ao $5^{\circ}$ ano E. F. & 286 & 5905,82 \\
\hline 2 & Henrique Pereira da Silva & M & $1^{\circ}$ ao $5^{\circ}$ ano E. F. & 314 & 5308,12 \\
\hline 3 & João Queiroz & M & $1^{\circ}$ ao $9^{\circ}$ ano E. F. & 426 & 3900,00 \\
\hline 4 & Dalci Barros Milhomens & M & $1^{\circ}$ ao $5^{\circ}$ ano E. F. & 128 & 3910,00 \\
\hline 5 & Hermínio Azevedo Soares & M & 1 ao 9 ano E. F. & 501 & 4212,92 \\
\hline 6 & Dom Alano & M & $1^{\circ}$ ao $5^{\circ}$ ano E. F. & 251 & 1578,79 \\
\hline 7 & Bendito Pereira Bandeira & $\mathrm{E}$ & $6^{\circ}$ ao $3^{\circ}$ ano E. M. & 302 & 4157,76 \\
\hline 8 & Gercina Borges Teixeira & $\mathrm{E}$ & $3^{\circ}$ ao $9^{\circ}$ ano E. F. & 500 & 3448,90 \\
\hline 9 & Colégio Estadual Tiradentes & $\mathrm{E}$ & $9^{\circ}$ ao $3^{\circ}$ ano E. M. & 565 & 4500,00 \\
\hline
\end{tabular}

$\mathrm{N}^{\circ}$ : Número de identificação; M: Escola Municipal; E: Escola Estadual.

\section{Coleta de dados}

No período de fevereiro a abril de 2014, as nove escolas foram visitadas. Em cada unidade escolar foi medida a área do pátio com o auxílio de trena de 50m para saber a área útil. Com relação à vegetação, fez-se o censo das espécies arbóreas existentes nos pátios das respectivas escolas, onde se coletou a altura e o diâmetro da copa e também dados referente a identificação de cada espécie de árvore, para a posterior identificação.

Para a identificação das espécies foram utilizados registros fotográficos das árvores avaliadas e coletadas amostras botânicas para serem comparadas com bibliografias especializadas, e também consulta ao Herbário de Porto Nacional - TO. Com relação à origem as mesmas foram classificadas em exóticas e nativas. Sendo consideradas nativas aquelas pertencentes à flora brasileira, cuja categorização se deu por meio de bibliografias especializadas, tais como Lorenzi (2003) e Lorenzi (2008). Para as famílias botânicas seguiu-se a classificação APG (APG III, 2009). Após a contabilização dos indivíduos foi calculada a frequência relativa de cada espécie pela razão entre o número de indivíduos da espécie e o número total de espécimes, multiplicada por 100 (FREITAS; MAGALHÃES, 2012).

Com relação à altura das árvores foram considerados todos os indivíduos arbóreos com altura igual ou superior a $1,80 \mathrm{~m}$, sendo as medidas realizadas com o auxílio do equipamento Clinômetro Haglöf. E para a área de copa das espécies arbóreas foram medidas as projeções das copas de cada exemplar, sendo registrados os valores dos dois eixos perpendiculares entre si com o auxílio de uma trena de $20 \mathrm{~m}$, para posteriormente calcular a projeção da área da copa em $\mathrm{m}^{2}$.

Tabela 2. Lista das espécies arbóreas encontradas nas nove escolas de Formoso do Araguaia (TO), e a classificação segundo a família, nome científico, nome popular, número de indivíduos (NI), Frequência (F\%) e origem (O), nativas (N) e exóticas (E).

\begin{tabular}{|c|c|c|c|c|c|}
\hline Família & Nome científico & Nome popular & NI & $\mathrm{F}(\%)$ & $\mathrm{O}$ \\
\hline \multirow[t]{3}{*}{ Anacardiaceae } & Anacardium occidentalle L. & Caju & 12 & 7,60 & $\mathrm{~N}$ \\
\hline & Mangifera indica $\mathrm{L}$. & Manga & 34 & 21,52 & $\mathrm{E}$ \\
\hline & Tabebuia aurea (Silva Manso) Benth. \& & & & & \\
\hline \multirow[t]{3}{*}{ Bignoniaceae } & Hook. f. ex S. Moore & Craibeira & 1 & 0,63 & $\mathrm{~N}$ \\
\hline & Tabebuia impetiginosa (Mart.Ex.Dc.) Stand. & Ipê-roxo & 3 & 1,90 & $\mathrm{~N}$ \\
\hline & Tabebuia roseoalba (Ridl.) Sandwith & Ipê- branco & 4 & 2,53 & $\mathrm{~N}$ \\
\hline Chrysobalanaceae & Licania tomentosa (Benth.) Fritsch & Oiti & 28 & 17,72 & $\mathrm{~N}$ \\
\hline Cupressaceae & Thuja orientalis L. & Tuia-da-china & 1 & 0,63 & $\mathrm{E}$ \\
\hline \multirow[t]{3}{*}{ Fabaceae } & Caesalpinia echinata Lam. & Pau-brasil & 3 & 1,90 & $\mathrm{~N}$ \\
\hline & Caesalpinia peltophoroides Benth. & Sibipiruna & 4 & 2,53 & $\mathrm{~N}$ \\
\hline & Cassia fistula $\mathrm{L}$. & Cássia-imperial & 29 & 18,35 & $\mathrm{E}$ \\
\hline
\end{tabular}

Revista Verde, v.12, n.2, p.218-226, 2017

\section{Cálculos dos índices arbóreo das escolas}

Após a coleta dos dados, os mesmos foram tabulados em planilhas Microsoft Excel, onde se fez os cálculos. Os índices arbóreos foram calculados baseados na metodologia proposta por Lima Neto e Souza (2009) e Callejas et al. (2014), conforme descritos abaixo:

- Índice de Densidade Arbóreo (IDA) consiste no cálculo do número de árvores existentes a cada $100 \mathrm{~m}^{2} \mathrm{em}$ razão da área total escolar (LIMA NETO; SOUZA, 2009), calculado pela expressão: IDA $=\frac{\mathrm{N}^{\circ} \text { árvores }}{\mathrm{AT}\left(\mathrm{m}^{2}\right)} \times 100$, onde: IDA $=$ Índice de Densidade Arbóreo; $\mathrm{N}^{\mathrm{o}}$ árvores = Número de árvores em cada escola; e $\mathrm{AT}\left(\mathrm{m}^{2}\right)=$ Área em $\mathrm{m}^{2}$ de cada escola.

- Índice de Sombreamento Arbóreo (ISA) refere-se à percentagem de área sombreada em relação à área total (LIMA NETO; SOUZA, 2009), calculado pela expressão: ISA $=\frac{\operatorname{AS}\left(\mathrm{m}^{2}\right)}{\mathrm{AT}\left(\mathrm{m}^{2}\right)} \times 100$, onde: ISA=Índice de Sombreamento Arbóreo; AS $\left(\mathrm{m}^{2}\right)$ = Área ocupada pela projeção das copas das árvores; e AT $\left(\mathrm{m}^{2}\right)=$ Área em $\mathrm{m}^{2}$ de cada escola.

- Índice de Área Verde (IAV) foi considerado o somatório das áreas de copa e expresso em $\mathrm{m}^{2}$ (CALLEJAS et al., 2014). O Índice de Área Verde escolar (IAVE) pode ser calculado pela expressão: IAVE $=\frac{\mathrm{AS}\left(\mathrm{m}^{2}\right)}{\text { Alunos matriculados }}$, onde: IAVE= Índice de Área Verde Escolar; e AS $\left(\mathrm{m}^{2}\right)=$ Área ocupada pela projeção das copas das árvores.

\section{RESULTADOS E DISCUSSÃO}

No levantamento arbóreo realizado nas nove escolas de Formoso do Araguaia - TO identificou-se 158 indivíduos dos quais $50 \%$ são nativos da flora brasileira. Sendo distribuídos em 14 famílias e 27 espécies, representadas por 15 nativas $(55,5 \%)$ e 12 exóticas $(44,5 \%)$, (Tabela 2$)$. 


\begin{tabular}{|c|c|c|c|c|c|}
\hline & Clitoria fairchildiana R.A.Howard & Sombreiro & 1 & 0,63 & $\mathrm{~N}$ \\
\hline & Delonix regia (Boj. ex Hook.) Raf. & Flamboyant & 1 & 0,63 & $\mathrm{E}$ \\
\hline & Inga nobilis Willd. & Ingá-bravo & 2 & 1,27 & $\mathrm{~N}$ \\
\hline & Tamarindus indica $\mathrm{L}$. & Tamarindo & 3 & 1,90 & $\mathrm{E}$ \\
\hline \multirow[t]{2}{*}{ Lauraceae } & Cinamomum zeylanicum Blume & Canela & 1 & 0,63 & $\mathrm{E}$ \\
\hline & Persea americana mill. & Abacate & 1 & 0,63 & $\mathrm{E}$ \\
\hline Malpighiaceae & Lophantera lactescens Ducke & Chuva-de-ouro & 7 & 4,43 & $\mathrm{~N}$ \\
\hline \multirow[t]{2}{*}{ Malvaceae } & Eriotheca phentaphilla (Vell.) A. Robyns & Paineira-pentafila & 3 & 1,90 & $\mathrm{~N}$ \\
\hline & Pachira aquatica Aubl. & Mungunba & 1 & 0,63 & $\mathrm{~N}$ \\
\hline Meliaceae & Azadirachta indica A. Juss & $\mathrm{Nim}$ & 2 & 1,27 & $\mathrm{E}$ \\
\hline Moraceae & Artocarpus heterophillus Lam. & Jaca & 1 & 0,63 & $\mathrm{E}$ \\
\hline \multirow[t]{2}{*}{ Myrtaceae } & Psidium guajava $\mathrm{L}$ & Goiaba & 7 & 4,43 & $\mathrm{~N}$ \\
\hline & Syzygium malaccense (L.) Merr \& Perry & Jambo-vermelho & 3 & 1,90 & $\mathrm{E}$ \\
\hline \multirow[t]{2}{*}{ Rutaceae } & Citrus limonia Osbeck & Limão-cravo & 2 & 1,27 & $\mathrm{E}$ \\
\hline & Citrus sinensis L. Osbeck & Laranja & 1 & 0,63 & $\mathrm{E}$ \\
\hline Simaroubaceae & Simarouba versicolor A. St.-Hil & Morcegueira & 1 & 0,63 & $\mathrm{~N}$ \\
\hline Sterculiaceae & Guazuma ulmifolia Lam. & Mutamba & 2 & 1,27 & $\mathrm{~N}$ \\
\hline Total Geral $=14$ & 27 & & 158 & 100 & \\
\hline
\end{tabular}

$\mathrm{Na}$ maioria das escolas avaliadas de Formoso do Araguaia, Tocantins, apesar da predominância de espécies nativas, foi constatada grande utilização de espécies exóticas (45\%). Entretanto, na escola Estadual Professor Vicente Lopes Perez em Monte Carmelo, MG, Santos e Lopes (2010) verificaram que a população de exóticas foi a que teve maior expressão $(73,3 \%)$. Segundo os referidos autores, isso se justifica devido ao desconhecimento por parte da população sobre as espécies nativas do Cerrado para serem utilizadas na arborização. Além disso, os autores relataram também que a realização de trabalhos como estes têm a sua importância, pois auxiliam na formação dos alunos e desperta o interesse pela preservação do ambiente e a prioridade do uso de espécies nativas.

Quando comparado os dados das escolas de Formoso do Araguaia, 55\% de espécies nativas, com as escolas de Lages inventariadas por Küster et al. (2012) percebe-se que a quantidade de nativas nestas escolas foi ainda menor (43\%). Tais dados revelam que a proporção entre espécies nativas e exóticas variam entre as diferentes regiões, ademais Biondi et al. (2008) destacam que o excesso de espécies exóticas pode prejudicar a biodiversidade local.

Outro fator importante a ser considerado é não arborizar escolas com espécies que apresentem espinhos, acúleos ou folhas pontiagudas devido apresentarem potencial de causar acidentes nas crianças (KÜSTER et al., 2012). Algumas dessas espécies exóticas como: Citrus limonia Osbeck (Limão-cravo) e Citrus sinensis L. Osbeck (laranja) foram encontradas nas escolas de Formoso do Araguaia - TO. Tais espécies também foram empregadas na arborização das escolas de Curitiba, Paraná (BIONDI et al., 2008).

Portanto, o plantio de espécies nativas, principalmente, símbolos do Brasil, como as espécies do gênero Tabebuia (Ipê) e Caesalpinia echinata Lam. (Pau-brasil) e Parkia pendula (Willd.) Benth. ex Walp (Fava de bolota) que é o símbolo do estado do Tocantins, são relevantes e ainda podem ser utilizadas nas atividades pedagógicas.

Mediante o exposto, é importante estabelecer critérios para arborizar o ambiente utilizando espécies arbóreas nativas da região, pois o ambiente quando bem arborizado melhora a estética do lugar, ameniza a temperatura, aumenta a umidade e purifica o ar (MUNEROLI; MASCARÓ, 2010) e, no caso das escolas, serve também como área de recreação e aprendizagem.

As escolas, Municipal Silas Raimundo Milhomem dos Santos, Municipal Henrique Pereira da Silva, Estadual Bendito Pereira Bandeira e Estadual Colégio Estadual Tiradentes apresentaram em comum a predominância de uma espécie nativa, a qual foi representada por Licania tomentosa (Benth.) Fritsch com as porcentagens 28,57; 29,17; 77,0 e $36,36 \%$, respectivamente, conforme apresentado na Tabela 3.

Tabela 3. Lista das espécies arbóreas em quatro escolas em Formoso do Araguaia (TO), distribuídas por número de indivíduos $(\mathrm{NI})$, frequência $(\mathrm{F} \%)$ e origem em nativas $(\mathrm{N})$ e exóticas $(\mathrm{E})$.

\begin{tabular}{|c|c|c|c|c|}
\hline Escolas & Espécie & NI & $\mathrm{F} \%$ & Origem \\
\hline \multirow{7}{*}{$\begin{array}{l}\text { Municipal Silas Raimundo Milhomem dos } \\
\text { Santos }\end{array}$} & Anacardium occidentalle L. & 1 & 14,29 & $\mathrm{~N}$ \\
\hline & Erioteca phentaphila (Vell.) A. Robyns & 1 & 14,29 & $\mathrm{~N}$ \\
\hline & Licania tomentosa (Benth.) Fritsch & 2 & 28,57 & $\mathrm{~N}$ \\
\hline & Mangifera indica $\mathrm{L}$. & 1 & 14,29 & $\mathrm{E}$ \\
\hline & Psidium guajava $\mathrm{L}$. & 1 & 14,29 & $\mathrm{~N}$ \\
\hline & Tamarindus indica $\mathrm{L}$. & 1 & 14,29 & $\mathrm{E}$ \\
\hline & Total & 7 & 100 & $4(N) 2(E)$ \\
\hline \multirow{6}{*}{ Municipal Henrique Pereira da Silva } & Anacardium occidentalle L. & 3 & 12,5 & $\mathrm{~N}$ \\
\hline & Licania tomentosa (Benth.) Fritsch & 7 & 29,17 & $\mathrm{~N}$ \\
\hline & Lophantera lactescens Ducke & 2 & 8,33 & $\mathrm{~N}$ \\
\hline & Mangifera indica $\mathrm{L}$. & 4 & 16,67 & $\mathrm{E}$ \\
\hline & Psidium guajava $\mathrm{L}$. & 2 & 8,33 & $\mathrm{~N}$ \\
\hline & Simarouba versicolor A. St.hil & 1 & 4,17 & $\mathrm{~N}$ \\
\hline
\end{tabular}




\begin{tabular}{|c|c|c|c|c|}
\hline & Syzygium malaccense L. & 2 & 8,33 & $\mathrm{E}$ \\
\hline & Tabebuia roseoalba (Ridl.) Sandwith & 3 & 12,5 & $\mathrm{~N}$ \\
\hline & Total & 24 & 100 & $6(N) 2(E)$ \\
\hline \multirow{6}{*}{ Estadual Bendito Pereira Bandeira } & Eriotheca pentaphylla (Vell.) A. Robyns & 1 & 6,25 & $\mathrm{~N}$ \\
\hline & Licania tomentosa (Benth.) Fritsch & 12 & 75 & $\mathrm{~N}$ \\
\hline & Mangifera indica $\mathrm{L}$. & 1 & 6,25 & $\mathrm{E}$ \\
\hline & Pachira aquatica Aubl. & 1 & 6,25 & $\mathrm{~N}$ \\
\hline & Thuja orientalis L. & 1 & 6,25 & $\mathrm{E}$ \\
\hline & Total & 16 & 100 & $3(\mathrm{~N}) 2(\mathrm{E})$ \\
\hline \multirow{8}{*}{ Estadual Colégio Estadual Tiradentes } & Anacardium occidentalle L. & 1 & 9,09 & $\mathrm{~N}$ \\
\hline & Clitoria fairchildiana R. A. Howard & 1 & 9,09 & $\mathrm{~N}$ \\
\hline & Inga nobilis Willd. & 2 & 18,18 & $\mathrm{~N}$ \\
\hline & Licania tomentosa (Benth.) Fritsch & 4 & 36,36 & $\mathrm{~N}$ \\
\hline & Mangifera indica L. & 1 & 9,09 & $\mathrm{E}$ \\
\hline & Psidium guajava L. & 1 & 9,09 & $\mathrm{~N}$ \\
\hline & $\begin{array}{l}\text { Tabebuia aurea (Silva Manso) Benth. \& Hook. f. ex } \\
\text { S. Moore }\end{array}$ & 1 & 9,09 & $\mathrm{~N}$ \\
\hline & Total & 11 & 100 & $6(N) 1(E)$ \\
\hline
\end{tabular}

O uso excessivo de L. tomentosa na arborização também foi evidenciado nas praças públicas da cidade de Gurupi, Tocantins. Segundo Santos et al. (2013), a grande utilização da referida espécie se justifica devido a árvore apresentar copa frondosa mesmo no período seco e tolerar podas frequentes. Ademais, como o Estado do Tocantins está localizado na região tropical do Brasil onde as temperaturas são elevadas durante vários meses do ano, isso também influencia na grande aceitação da espécie já que fornece sombra o ano inteiro.

Ao identificar a vegetação da escola Municipal João Queiroz notou-se que houve dominância de duas espécies: Mangifera indica L. e Cassia fistula L. e ao comparar a escola Municipal João Queiroz com a Estadual Gercina Borges Teixeira verificou-se que as mesmas têm em comum a $M$. indica L. cuja frequência de distribuição foi 36,36 e $71,43 \%$, respectivamente (Tabela 4 ).

Tabela 4. Lista das espécies arbóreas em duas escolas em Formoso do Araguaia (TO), distribuídas por número de indivíduos (NI), frequência (F\%) e origem em nativas $(\mathrm{N})$ e exóticas $(\mathrm{E})$

\begin{tabular}{|c|c|c|c|c|}
\hline Escola & Espécie & NI & F\% & Origem \\
\hline \multirow{7}{*}{ Municipal João Queiroz } & Cassia fistula $\mathrm{L}$. & 8 & 36,36 & $\mathrm{E}$ \\
\hline & Licania tomentosa (Benth.) Fritsch. & 1 & 4,55 & $\mathrm{~N}$ \\
\hline & Mangifera indica $\mathrm{L}$. & 8 & 36,36 & $\mathrm{E}$ \\
\hline & Persea americana Mill. & 1 & 4,55 & $\mathrm{E}$ \\
\hline & Tabebuia impetiginosa (Mart. Ex. Dc.) Stand & 3 & 13,64 & $\mathrm{~N}$ \\
\hline & Tabebuia roseoalba (Ridl.) Sandwith & 1 & 4,55 & $\mathrm{~N}$ \\
\hline & Total & 22 & 100 & $3(\mathrm{~N}) 3(\mathrm{E})$ \\
\hline \multirow{6}{*}{ Estadual Gercina Borges Teixeira } & Artocarpus heterophyllus Lam. & 1 & 7,14 & $\mathrm{E}$ \\
\hline & Cinamomum zeylanicum Blume & 1 & 7,14 & $\mathrm{E}$ \\
\hline & Lophantera lactescens & 1 & 7,14 & $\mathrm{~N}$ \\
\hline & Mangifera indica $\mathrm{L}$. & 10 & 71,43 & $\mathrm{E}$ \\
\hline & Syzygium malaccense L. & 1 & 7,14 & $\mathrm{E}$ \\
\hline & Total & 14 & 100 & $1(\mathrm{~N}) 4(\mathrm{E})$ \\
\hline
\end{tabular}

Apesar de ser uma espécie exótica, Mangifera indica L. também teve alta representatividade na escola de Cuiabá MT, representando $37 \%$ da população, cujo fato se deve à facilidade de adaptação ao clima local (CALLEJAS et al., 2014). O mesmo se aplica a cidade se Gurupi, no Tocantins, já que a mesma faz parte da arborização das praças públicas (SANTOS et al., 2013), o que também sugere a grande utilização dessa árvore nas escolas de Formoso do Araguaia.

Nas escolas Municipais Dalci Barros Milhomens, Hermínio Azevedo Soares e Dom Alano também foram evidenciados a predominância de determinada(s) espécie(s), sendo Anacardium occidentalle L. e Lophantera lactescens Ducke encontradas na primeira escola, representando $25 \%$ da população cada uma; Cassia fistula L. com 51,21\% na segunda e Caesalpinia peltophoroides Benth com 57,14\%, na última. Pelos resultados observou-se que há uma variabilidade quanto aos tipos de plantas empregadas na arborização das escolas, que vai desde frutíferas comestíveis até árvores florestais de grande porte, sejam nativas ou exóticas (Tabela 5). 
Tabela 5. Lista das espécies arbóreas em três escolas em Formoso do Araguaia (TO), distribuídas por número de indivíduos (NI), frequência (F\%) e origem em nativas $(\mathrm{N})$ e exóticas $(\mathrm{E})$

\begin{tabular}{|c|c|c|c|c|}
\hline Escola & Espécie & $\mathrm{NI}$ & $\mathrm{F} \%$ & Origem \\
\hline \multirow{9}{*}{ Municipal Dalci Barros Milhomens } & Anacardium occidentalle $\mathrm{L}$. & 4 & 25 & $\mathrm{~N}$ \\
\hline & Azadirachta indica A. Juss & 2 & 12,5 & $\mathrm{E}$ \\
\hline & Caesalpinia echinata Lam. & 2 & 12,5 & $\mathrm{~N}$ \\
\hline & Delonix regia (Boj. Ex Hook.) Raf. & 1 & 6,25 & $\mathrm{E}$ \\
\hline & Licania tomentosa (Benth) Fritsch. & 1 & 6,25 & $\mathrm{~N}$ \\
\hline & Lophantera lactescens Ducke & 4 & 25 & $\mathrm{~N}$ \\
\hline & Mangifera indica L. & 1 & 6,25 & $\mathrm{E}$ \\
\hline & Psidium guajava L. & 1 & 6,25 & $\mathrm{~N}$ \\
\hline & Total & 16 & 100 & $5(N) 3(E)$ \\
\hline \multirow{10}{*}{ Municipal Hermínio Azevedo Soares } & Anacardium occidentalle $\mathrm{L}$ & 3 & 7,32 & $\mathrm{~N}$ \\
\hline & Cassia fistula $\mathrm{L}$. & 21 & 51,22 & $\mathrm{E}$ \\
\hline & Citrus limonea Osbeck & 2 & 4,88 & $\mathrm{E}$ \\
\hline & Erioteca Phentafila (Vell.) a. Robyns & 1 & 2,44 & $\mathrm{~N}$ \\
\hline & Guazuma ulmifolia Lam. & 2 & 4,88 & $\mathrm{~N}$ \\
\hline & Licania tomentosa (Benth) Fritsch. & 1 & 2,44 & $\mathrm{~N}$ \\
\hline & Mangifera indica $\mathrm{L}$. & 7 & 17,07 & $\mathrm{E}$ \\
\hline & Psidium guajava L. & 2 & 4,88 & $\mathrm{~N}$ \\
\hline & Tamarindus indica $\mathrm{L}$. & 2 & 4,88 & $\mathrm{E}$ \\
\hline & Total & 41 & 100 & $5(N) 4(E)$ \\
\hline \multirow{5}{*}{ Municipal Dom Alano } & Caesalpinia echinata Lam. & 1 & 14,29 & $\mathrm{~N}$ \\
\hline & Caesalpinia peltophoroides Benth. & 4 & 57,14 & $\mathrm{~N}$ \\
\hline & Citrus sinensis L. Osbeck & 1 & 14,29 & $\mathrm{E}$ \\
\hline & Mangifera indica $\mathrm{L}$. & 1 & 14,29 & $\mathrm{E}$ \\
\hline & Total & 7 & 100 & $2(\mathrm{~N}) 2(\mathrm{E})$ \\
\hline
\end{tabular}

E dentre as escolas avaliadas, a Hermínio Azevedo Soares e a Dom Alano foram as que apresentaram a maior e a menor quantidade de indivíduos e espécies arbóreas, respectivamente. A explicação provável de haver menos árvores na escola Dom Alano se deve ao reduzido espaço físico $\left(1578,79 \mathrm{~m}^{2}\right)$.

Com relação a diversidade de espécies para a arborização, Silva et al. (2007) aconselham que a porcentagem de indivíduos por espécie deve ficar compreendido na faixa entre 12 a $15 \%$, já que uma população homogênea está sujeita ao ataque de pragas e doenças específicas. Tomando como base o exposto, pode-se constatar que a frequência relativa da população arbórea de todas as escolas avaliadas está fora do recomendado, cuja frequência variou de 25 a $75 \%$ e sendo representadas pelas espécies: Licania tomentosa (Benth.) Fritsch (Oiti), Mangifera indica L. (Mangueira) e Cassia fistula L. (Cassia imperial), Caesalpinia peltophoroides Benth. (Sibipiruna) e Anacardium occidentalle L. (Caju).

A quantidade de espécies exóticas encontradas na escola Gercina Borges Teixeira foi superior às nativas, isso mostra que a vegetação da referida instituição de ensino não reflete a diversidade da flora brasileira, enquanto, nas demais escolas, Silas Raimundo Milhomem dos Santos, Henrique Pereira da Silva, Dalci Barros Milhomens, Hermínio Azevedo Soares, Bendito Pereira Bandeira e Colégio Estadual Tiradentes, o resultado encontrado foi o inverso, com exceção das escolas João Queiroz e Dom Alano, que apresentou 50\% (Figura 2).

Figura 2. Representação gráfica do número de espécies nativas e exóticas nas escolas avaliadas de Formoso do Araguaia (TO). Escolas: 1- Silas Raimundo Milhomem dos Santos; 2- Henrique Pereira da Silva; 3- João Queiroz; 4- Dalci Barros Milhomens; 5- Hermínio Azevedo Soares; 6- Dom Alano; 7- Bendito Pereira Bandeira; 8- Gercina Borges Teixeira; 9- Colégio Estadual Tiradentes

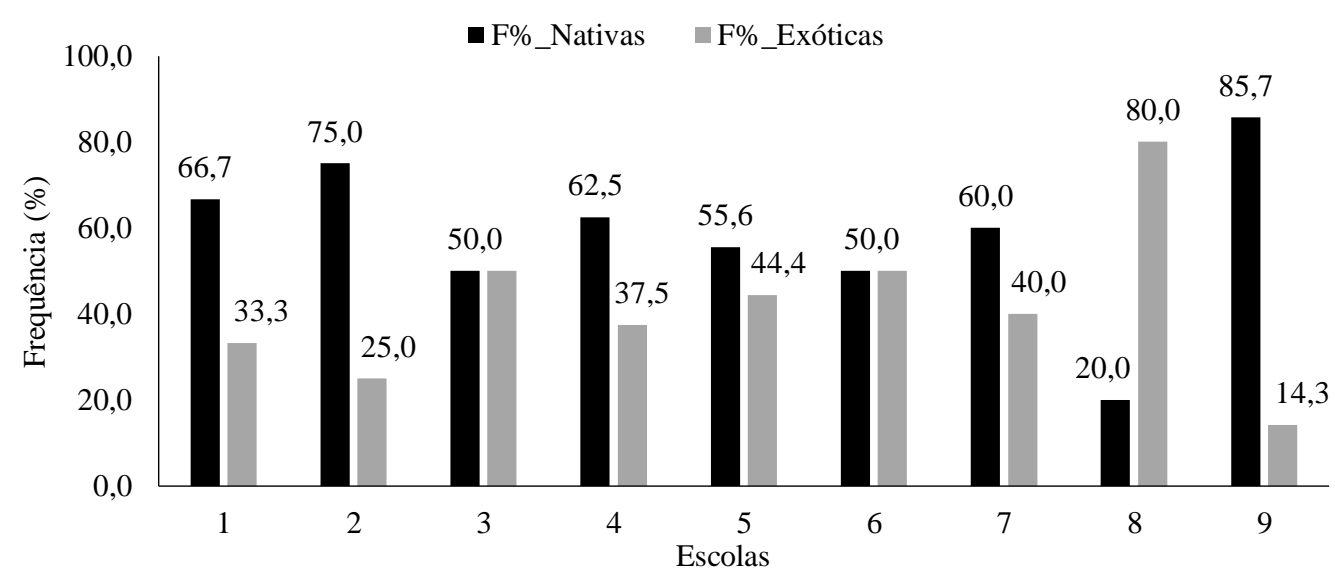


Pode-se constatar que na maioria nas escolas avaliadas predominou o uso de espécies nativas. Entretanto, é importante o maior uso de espécies arbóreas nos pátios escolares que represente a biodiversidade brasileira e expresse valores da cultura local, cujas espécies podem ser usadas para ilustrar conhecimentos teóricos da educação ambiental, dinâmica da paisagem, as interações flora-fauna e a importância histórica e econômica destas (CADORIN et al., 2011).

O uso de índices arbóreos para avaliar a arborização de pátios escolares também se faz necessário, tais como: IDA, ISA e IAVE. Nas análises dos índices arbóreos observou-se que as escolas Hermínio Azevedo Soares e Silas Raimundo Milhomem dos Santos apresentaram o maior e o menor Índice de Densidade Arbóreo (IDA) sendo de 0,973 e 0,119 árvores para cada $100 \mathrm{~m}^{2}$, respectivamente (Tabela 6). Assim, dentre as escolas avaliadas apenas a Hermínio Azevedo Soares apresentou o valor próximo de 1 (uma) árvore para cada 100 $\mathrm{m}^{2}$, necessitando de apenas mais um indivíduo para está de acordo com o recomendado por Lima Neto e Souza (2009), enquanto o baixo IDA verificado na escola Silas Raimundo Milhomem dos Santos se justifica devido à baixa quantidade de árvores (7 indivíduos) e também por apresentar a maior área plana $\left(5905,82 \mathrm{~m}^{2}\right.$, tabela 1$)$.

Tabela 6. Índices arbóreos da arborização, número de árvores atuais, número de árvores ideal para que o IDA seja igual a 1,0 indivíduo por $100 \mathrm{~m}^{2}$ nas nove escolas de Formoso do Araguaia, Tocantins

\begin{tabular}{lccccc}
\hline ESCOLA & $\begin{array}{c}\text { IDA } \\
(\%)\end{array}$ & $\begin{array}{c}\mathrm{N}^{\circ} \text {. árvores } \\
\text { Atual }\end{array}$ & $\begin{array}{c}\mathrm{N}^{\circ} \text {. árvores } \\
\text { Ideal }\end{array}$ & $\begin{array}{c}\text { ISA } \\
(\%)\end{array}$ & $\begin{array}{c}\text { IAVE } \\
\left(\mathrm{m}^{2} / \mathrm{aluno}\right)\end{array}$ \\
\hline 1-Silas Raimundo Milhomem dos Santos & 0,119 & 7 & 59 & 3,587 & 0,741 \\
2-Henrique Pereira da Silva & 0,452 & 24 & 53 & 9,930 & 1,679 \\
3-João Queiroz & 0,564 & 22 & 39 & 28,193 & 2,581 \\
4-Dalci Barros Milhomens & 0,409 & 16 & 39 & 9,077 & 2,773 \\
5-Hermínio Azevedo Soares & 0,973 & 41 & 42 & 19,037 & 1,601 \\
6-Dom Alano & 0,443 & 7 & 15 & 17,608 & 1,108 \\
7-Bendito Pereira Bandeira & 0,356 & 16 & 41 & 6,000 & 0,478 \\
8-Gercina Borges Teixeira & 0,406 & 14 & 34 & 11,741 & 0,810 \\
9-Colégio Estadual Tiradentes & 0,265 & 11 & 45 & 8,477 & 1,167 \\
\hline
\end{tabular}

IDA- índice de densidade arbóreo; ISA- Índice de sombreamento arbóreo; IAVE- índice de área verde escolar.

O valor 0,973 da escola Hermínio Azevedo Soares é considerado bom quando comparado com as demais que apresentam menor quantidade de árvores. Portanto, tais resultados sugerem a necessidade de adotar medidas para implantar projetos de arborização nessas escolas a fim de melhorar a densidade de árvores e ainda proporcionar um ambiente de lazer, aprendizagem e conforto térmico.

Quanto ao índice de sombreamento arbóreo (ISA) podese observar que os maiores valores foram encontrados na escola João Queiroz $(28,193 \%)$ e Hermínio Azevedo Soares (19,037\%), enquanto, o menor índice foi atribuído a escola Silas Raimundo Milhomem dos Santos (3,587\%). De acordo com os resultados pode-se constatar a ausência e a menor quantidade de árvores em todas as escolas, entretanto, a João Queiroz foi a que apresentou o maior índice. Mesmo assim, ainda é considerado baixo já que o valor ideal do ISA deve ser superior a $30 \%$ para áreas destinadas a fins comerciais e $50 \%$ para as residenciais (SIMÕES et al., 2001).

Diferentemente deste estudo, os valores de índice de sombreamento arbóreo encontrado por Callejas et al. (2014) variam de 9,26 e $33,40 \%$, ou seja, pelo menos uma escola estava dentro do valor considerado ideal por Simões et al. (2001). No entanto, é importante destacar que o maior ISA está diretamente relacionado ao número de árvores e ao tamanho da copa. Assim, Callejas et al. (2014) tomando como base o índice de densidade arbórea de um indivíduo para cada $100 \mathrm{~m}^{2}$ propôs o ISA superior a $40 \%$ para a implantação de projetos de arborização em escolas.

Pelos resultados pode-se inferir que a escola João Queiroz foi a que proporcionou maior sombreamento amenizando a temperatura local, o que se justifica devido à quantidade de árvores no local serem bem distribuída em relação ao espaço físico, especialmente devido a dominância de Mangifera indica L. que possui copa grande e frondosa. Enquanto, a escola Hermínio Azevedo Soares possui o segundo maior ISA, justificado devido possuir a maior quantidade de árvores (41) dentre todas as escolas avaliadas, o que vem a compensar a sua área física de 4212,92 $\mathrm{m}^{2}$. Entretanto, a escola Silas Raimundo Milhomem dos Santos foi a que apresentou menor ISA devido à reduzida quantidade de árvores (7) e a maior área escolar $\left(5.905,8 \mathrm{~m}^{2}\right)$, quando comparada com as demais.

O sombreamento arbóreo influencia diretamente na melhoria das condições térmicas das salas de aula, pois as árvores são responsáveis por redução da temperatura dos ambientes internos em até $2^{\circ} \mathrm{C}$. Comprovando que as plantas amenizam as temperaturas internas e externas do ambiente, e quando fazem sombras nas paredes das construções pode reduzir a demanda anual de energia elétrica para refrigerar as salas, as quais demonstram a importância da arborização, especialmente em cidades de clima quente (DURANTE, 2011), como Formoso do Araguaia, no Tocantins

Outro aspecto relevante é a localização das árvores nos pátios das escolas, pois neste estudo constatou-se que a maior parte dos indivíduos estavam plantados nas proximidades de muros, e como consequência do plantio sem o devido planejamento foi observado à existência de podas corretivas que levam a redução da área de copa, cuja prática influencia negativamente o índice de sombreamento arbóreo.

Portanto, nos próximos plantios a serem realizados nas escolas: Silas R. M. dos Santos, Henrique P. da Silva; João Queiroz, Dalci B. Milhomens, Hermínio A. Soares, Dom Alano, Bendito P. Bandeira, Gercina B. Teixeira e Colégio E. Tiradentes deve-se adotar critérios quanto à escolha das espécies e do espaço físico onde cada indivíduo botânico será implantado. Pois quando a finalidade do plantio é promover a interação e o conforto térmico, recomenda-se que as árvores sejam implantadas nas áreas externas de convivência e de maior permanência de alunos e funcionários (CALLEJAS et al., 2014). 
Quanto ao índice de área verde escolar (IAVE) foram encontrados valores muito baixo, variando de 0,478 a 2,773 $\mathrm{m}^{2}$ /aluno, destacando-se a escola Dalci Barros Milhomens por apresentar o maior valor e mais uma vez a escola Silas Raimundo Milhomem dos Santos por apresentar o menor índice arbóreo (Tabela 6). Como a obtenção desse índice se dá pela razão entre área total de sombra projetada pela copa das árvores em relação ao número de habitantes (alunos) justifica-se a obtenção do maior índice na escola Dalci Barros Milhomens, pois o IVAE é inversamente proporcional ao número de alunos, ou seja, quanto menor o número de alunos maior será o IVAE.

A explicação para o baixo IAVE em todas as escolas avaliadas é o reflexo da pequena quantidade de árvores plantadas, tais valores devem servir de alerta para que novas espécies florestais sejam implantadas nesses ambientes, cuja prática pode ser realizada pela própria comunidade escolar envolvendo a participação de alunos e professores.

Para as áreas verdes, a Sociedade Brasileira de Arborização Urbana - SBAU recomenda que o índice seja de $15 \mathrm{~m}^{2}$ por habitante (SBAU, 1996). Sabe-se que o pátio das escolas não se encaixa no conceito de área verde, e sim, como complemento a esse conceito. Sendo assim, tomando esse valor como referência é notório que o índice das escolas está aquém de promover conforto térmico para aqueles que usufruem do espaço. Assim como verificado no presente estudo em Formoso do Araguaia, contudo Callejas et al. (2014) propõe como satisfatório um IAVE para escolas de pelo menos $12 \mathrm{~m}^{2} /$ aluno.

Nesse estudo foi verificado a maior frequência das espécies Mangifera indica L., seguida de Licania tomentosa (Benth.) Fritsch e Cassia fistula L. e com relação aos índices arbóreos ficou provado que a escola João Queiroz apresentou a situação mais preocupante pois havia menos exemplares, e consequentemente índices baixos. A escola João Queiroz apresentou o melhor índice de sombreamento arbóreo (ISA) com 28,19\%, enquanto a escola Hermínio Azevedo Soares pode servir como referência tendo vista que se destacou por apresentar o maior número de indivíduos (41), os quais influenciaram diretamente nos altos índices arbóreos (ISA de 19,037\% e IDA 0,97\%). Esses resultados sugerem medidas de gestão para melhorar a arborização de todas as escolas, com a introdução de novas espécies, preferencialmente da flora nativa e melhorar a distribuição do número de indivíduos.

\section{CONCLUSÕES}

Todas as escolas apresentaram exemplares arbóreos. A espécie nativa mais frequente foi Licania tomentosa (Benth.) Fritsch e as exóticas foram representadas por Mangifera indica L. e Cassia fistula L.

Os maiores índices arbóreos (IDA e ISA) foram verificados nas escolas João Queiroz e Hermínio Azevedo Soares e o menor na Silas Raimundo Milhomem dos Santos.

\section{REFERÊNCIAS}

ALVES, A. C. N.; ANDRADE, T. C. Q.; NERY, J. M. F. G. A influência da vegetação e da ocupação do solo no clima urbano: um exercício analítico sobre a Avenida Paralela. Fórum Patrimônio, Belo Horizonte, v.4, n.1, p.43-52, 2011.
ANDRADE, R. T. G.; SILVA, A. C. C. Educação ambiental: uma perspectiva metodológica empregada pelo projeto nativas no campus da UFRN. Holos, Natal, v.1, ano 24, p.93118, 2008.

APG III. An update of the angiosperm phylogeny group classification for the orders and families of flowering plants: APG III. Botanical Journal of the Linnean Society, Londres, v.161, n.2, p.105-121, 2009.

BIONDI, D.; LEAL, L.; SCHAFFER, M. Aspectos importantes das plantas ornamentais em escolas públicas estaduais da cidade de Curitiba, PR. Revista Brasileira de Ciências Agrárias, Recife, v.3, p. 267-275, 2008.

BOLZAN, A. Z.; GRACIOLI, C. R. Ações de educação ambiental na escola municipal de ensino fundamental João Pessoa - São Sepé, RS. Revista Eletrônica em Gestão, Educação e Tecnologia Ambiental, Santa Maria, v.6, n. 6, p.1007-1014, 2012.

CADORIN, D. A., HASSE, I., SILVA, L. M., BETT, C. F. Características da flora arbórea de quatro escolas de Pato Branco-PR. Revista da Sociedade Brasileira de Arborização Urbana, Piracicaba, v.6, n.2, p.104-124, 2011.

CALlEJAS, I. J. A.; DURANTE, L.C.; OlIVEIRA, A. S.; NOGUEIRA, M. C. J. A. Diversidade e índices arbóreos em ambientes escolares. Revista Eletrônica em Gestão, Educação e Tecnologia Ambiental, Santa Maria, v.18, n.1, p.454-466, 2014.

DURANTE, L.C. Sombreamento arbóreo e desempenho termoenérgético de edificações. Cuiabá: UFMT, 2012. 228p.

FAGUNDES, J. F.; BANDEIRA, G. L.; SIQUEIRA, A. B.; NEIS, F. A.; KONFLANZ, T. L. Arborização e jardinagem na Escola Municipal de Ensino Fundamental Assis Brasil em Palmeira das Missões - RS. Revista Eletrônica em Gestão, Educação e Tecnologia Ambiental, Santa Maria, v.19, n.2, p.1162-1173, 2015.

FREITAS, W. K.; MAGALHÃES, L. M. Métodos e Parâmetros para Estudo da Vegetação com Ênfase no Estrato Arbóreo. Floresta e Ambiente, Seropédica, v.19, n.4, p.520540, 2012.

IBGE. INSTITUTO BRASILEIRO DE GEOGRAFIA E ESTATISTICA. Diretoria de Pesquisas, Coordenação de População e Indicadores Sociais. Estimativa populacional 2014. Rio de Janeiro: IBGE, 2014. Disponível em: <http://www.ibge.gov.br/home/estatistica/populacao/estimati va2014/estimativa_dou.shtm>. Acesso em 25 Jun. 2014.

KÜSTER, L. C.; STEDILLE, L. I. B.; DACOREGIO, H.; SILVA, A. C.; HIGUCHI, P. Avaliação de riscos e procedência de espécies arbóreas nas escolas estaduais de Lages, SC. Revista de Ciências Agroveterinárias, Lages, v.11, n.2, p. 118-125, 2012.

LIMA NETO, E. M.; SOUZA, R. M. Índices de densidade e sombreamento arbóreo em áreas verdes públicas de Aracaju, 
Sergipe. Revista da Sociedade Brasileira de Arborização Urbana, Piracicaba - SP, v.4, n.4, p.47-62, 2009.

LORENZI, H. Árvores exóticas no Brasil: madeireiras, ornamentais e aromáticas. 1.ed. Nova Odessa: Instituto Plantarum, 2003. 368p.

LORENZI, H. Árvores brasileiras: manual de identificação e cultivo de plantas arbóreas nativas do Brasil. 5.ed. Nova Odessa: Instituto Plantarum, 2008. 384p.

MUNEROLI, C. C.; MASCARÓ, J. J. Arborização urbana: uso de espécies arbóreas nativas na captura do carbono atmosférico. Revista da Sociedade Brasileira de Arborização Urbana, Piracicaba, v.5, n.1, p.160-182, 2010.

PAIVA, V. A; LIMA, A. B. M.; CARVALHO, A.; JUNIOR, A. M.; GOMES, A.; MELO, C. S. Inventário e diagnóstico da arborização urbana viária de Rio Branco, AC. Revista da Sociedade Brasileira de Arborização Urbana, Piracicaba, v.5, n.1, p.144-159, 2010.

SANTOS, A. F.; JOSÉ, A. C.; SOUSA, P. A. Fitossociologia e diversidade de espécies arbóreas das praças centrais do município de Gurupi - TO. Revista da Sociedade Brasileira de Arborização Urbana, Piracicaba, v.8, n.4, p.36-46, 2013.

SANTOS, K. A.; LOPES, S. F. Avaliação da arborização da escola estadual professor Vicente Lopes Perez, Monte Carmelo - MG. Cadernos da FUCAMP, Monte Carmelo, v.9, n.11, 2010. Disponível em: <http://www.fucamp.edu.br/editora/index.php/cadernos/articl e/view/178>. Acesso: 29 jan. 2015.

SILVA, A. G.; PAIVA, H. N.; GONÇALVES, W. Avaliando a arborização urbana. 1.ed. Viçosa: Aprenda Fácil, 2007. $346 p$.

SIMÕES, L. O. C.; MAROTTA, H.; PIRES, B. B. M.; UMBELINO, L. F.; COSTA, A. J. S. T. Índices de Arborização em espaço urbano: um estudo de caso no bairro de Vila Isabel, Rio de Janeiro, RJ. In: Encontro Nacional de Arborização Urbana, 9, 2001, Brasília. Anais ... Brasília: ABRH, 2001. CD Rom.

SBAU. SOCIEDADE BRASILEIRA DE ARBORIZAÇÃO URBANA. Carta a Londrina e Ibiporã. Boletim Informativo, v.3, n.5, p.3, 1996.

TOCANTINS, Secretaria do Planejamento e da Modernização da Gestão Pública. Atlas do Tocantins: subsídios ao planejamento da gestão territorial. 6.ed. Palmas: SEPLAN/DZE, 2012. 20p.

TOLEDO, F. S.; SANTOS, D. G. Espaços livres de construção. Revista da Sociedade Brasileira de Arborização Urbana, Piracicaba, v.3, n.1, p.73-91, 2008. 